\title{
DISABILITY, STATUS ENHANCEMENT, PERSONAL ENHANCEMENT AND RESOURCE ALLOCATION
}

\author{
Jonathan WolfF \\ University College London
}

It often appears that the most appropriate form of addressing disadvantage related to disability is through policies that can be called "status enhancements": changes to the social, cultural and material environment so that the difficulties experienced by those with impairments are reduced, even eradicated. However, status enhancements can also have their limitations. This paper compares the relative merits of policies of status enhancement and "personal enhancement": changes to the disabled person. It then takes up the question of how to assess the priority of the claims of disabled people in the face of scarcity of resources for which there can be many competing social claims, arguing for the theory of "declustering disadvantage".

\section{INTRODUCTION}

Assuming that the disadvantage associated with disability should engage the concerns of egalitarians, how should a broadly egalitarian approach to political philosophy address issues of disability? Here I shall look at a number of related questions. First, what sorts of strategies are available? Second, what reasons are there for preferring one type of strategy to another? And third, how can we decide what proportion of society's scarce resources should be devoted to the task of addressing problems caused by disability?

This paper was first presented at a conference on Disability and Equal Opportunity at Bergen in 2006. I am very grateful to the participants for illuminating discussion. I am also very pleased to thank Peter Vallentyne, Luc Bovens, Bertil Tungodden, Andrew Williams and one further anonymous reader for this journal, for their remarkably incisive and helpful comments, criticisms and suggestions. 
It may seem that the first task of this paper should be to define disability, but little of what I say here depends on the fine contours of any particular definition. Instead I will set out some of the main features of the account of disability that I shall pre-suppose. Some elements could be treated as definitional and others as empirical claims about the effects of disability, but no current purpose is served by dwelling here on which are which.

First, and most obviously, disability is related to the idea of impairment; impairment of mental or physical functioning. Second, such impairment either leads to, or constitutes, adverse effects or consequences for the individual. Third, the causal connection between impairment and adverse consequences is (at least very often) mediated by a series of social, cultural and material factors. Often it will also be possible, at least in theory, to remove, mitigate or, conversely, aggravate, these adverse consequences by adjusting the mediating factors. Proponents of a radical "social model" of disability will argue that all adverse consequences of impairment - even the identification of a factor as an impairment - can be removed by suitable adjustments elsewhere. This is the view that "society disables individuals". No one, I think, would take the opposite extreme and argue that social factors can have no effect at all on the adverse consequences of impairment. Yet it is not uncommon for the social factors to be given little attention, and for it to be assumed that addressing disability should, wherever possible, be in the first instance addressed at "curing" the impairment. Such an approach is to adopt the "medical model" of disability. But the medical model, or at least a medical approach, can also be adopted for more theoretically informed reasons, such as scepticism at the scope for change possible through transformation of social, cultural and material factors, or for concern about the likely costs or other consequences of such action. Indeed, these critical arguments will be a central theme of the discussion to follow.

\section{ADDRESSING DISABILITY}

So far I hope that what I have said is entirely uncontroversial. Later on I will need to explore the nature of the "adverse consequences" that affect disabled people, but at this stage, once again, we can afford to be neutral, in that what follows in this section does not depend on any particular account. We need now to take up the question of what sort of action, in the form of social policy, could potentially address issues of disadvantage related to disability. At least four prominent possibilities can be distinguished (Wolff 2002, forthcoming). The first is cash compensation, in which money is provided to be used in whichever way the person wishes. A disabled person, we noted, suffers from adverse consequences of impairment. Cash compensation simply provides money to "make up for" these adverse consequences. Cash can allow the individual to find alternative, perhaps 
more expensive, means of achieving opportunities enjoyed by others, or to take advantage of other opportunities to compensate for the disability.

A second approach is "personal enhancement" in which action is taken directly on the impairment, by surgery, physiotherapy or training and so on. This, of course, is a traditional approach to disability, which we referred to as the "medical model" above. It assimilates disability to forms of illness and disease, and puts the implementation of policy into the hands of the medical profession.

What can be called "targeted resource enhancement" is the third approach, in which resources are made available to the disabled person. These can take the form of equipment, support from carers or family, or even money with strings attached about how it can be spent. Such a policy differs from cash compensation in the conditions attached to the grant of money or goods. Its point is to enable the disabled person to find alternative means of achieving the ends that are put in jeopardy through impairment. Hence the support is targeted in the sense that the resources are provided for a particular purpose and are restricted in their permitted uses. For example, those provided with a wheelchair from the state would not normally be permitted to sell it, use it to make a go-cart for their children, or even to give it away.

Finally, a fourth approach is what can be called "status enhancement" in which changes to social, material and cultural structure are made in order to modify the structural mediating factors between impairment and adverse consequences. An individual's status is improved in the sense that external barriers to achievement are removed and so the person will have a wider range of opportunities. The most obvious form of status enhancement is the removal of discriminatory laws and practices, such as laws discriminating against women, or members of minority races or religions. For disabled people, and especially those with mobility problems, status enhancement is also likely to take a material and cultural form. Physical access to places can be improved, technology can be adapted to meet the needs of a wider range of people, and employers, shop-keepers and other citizens can come to treat disabled people in the same way as they treat others. To the degree it is successful, status enhancement "cancels out" impairment, turning disability into "difference". It is important to note that, typically, status enhancement is a collective, rather than individualized, approach, in that it can improve the opportunities of many people without acting directly on any of them. In this way it differs from the other three strategies mentioned.

\section{CHOICE OF STRATEGIES}

Whatever the advantages of status enhancement, it is natural to think that where it is available, the more direct strategy of personal enhancement 
would be the better method to address disability. It appears to do so at its root, by removing physical or mental impairment in the most obvious fashion. Yet when we look at specific examples, our intuitions may not be so clear. Take, for example, people who are, as adults, very short, perhaps the height of young children. The position of light switches, shelves, bank counters and many other things are designed on the assumption that adults are within a certain height range. Those who fall outside this range have "impaired height", and are disabled as a result, because they will suffer adverse consequences of their impairment. The analysis of this paper suggests that if we wish to address their disability a range of strategies is, in theory, available. However, let us concentrate on the comparison between personal enhancement and status enhancement. Suppose, first, a medical solution is possible and that treatment with a pill would bring everyone to a normal height threshold. But let us also suppose that a second solution is available and we could redesign the physical and cultural environment so that there is no longer any sort of functional disadvantage in being shorter than the normal range. Suppose, on this approach, the physical world is sympathetically redesigned and at the same time any social stigma disappears. If both remedies were available, and abstracting from issues of cost, is it so obvious that society should prefer a medical cure? If height really had no further effects on marriage or job prospects, or one's overall chances of sporting success, ${ }^{1}$ many people, I believe, will share the intuition that status enhancement - changes to the social and material structure - is to be preferred to personal enhancement, which in this case is the medical cure. Indeed in this example the natural intuition in favour of personal enhancement seems to shift quite easily to an intuition in favour of status enhancement.

What, though, is the basis of this shift in support towards status enhancement? The most obvious thought is that a social policy requiring individuals to undergo physical change in order to function well encourages the idea that there is something wrong with such people, and that they need to be cured. This can be humiliating or stigmatizing, for people have to be identified as defective in order to seek help. Yet not all forms of intervention need be humiliating. For example, if the intervention happened very early - perhaps in the womb - then the problem of humiliation would be overcome. Suppose, for example, a painless and risk-free diagnostic test can be performed to identify whether a fetus has

${ }^{1}$ I am not supposing that, for example, we ban sports such as basketball in which height is a great advantage. Rather I am supposing that we also invent sports in which very short people have the advantage, and that these are just as much fun to play for amateurs and as lucrative for professionals. Indeed horse racing already provides one example, and the Paralympic movement, despite early ridicule, is having some success now in making similar changes. 
a vulnerability to restricted height, and a single pill can be taken by the pregnant mother so that the resulting child will be within the normal height range. Let me concede that such intervention is very unlikely to be experienced as stigmatizing, either by the mother or the resulting child, even at later stages in life. Intervention to prevent impairment, even among those especially vulnerable, seems much less likely to be stigmatizing than later intervention to correct it. Those, for example, who find that without a small operation they are likely to face a progressive, disabling, disease, may well find only relief, and no stigma at all, in being identified as at risk, and being given the opportunity to eliminate that risk through medicine or surgery. These examples suggest that stigma does not, or at least need not, attach to the need for medical help.

If it is true that medical interventions to prevent impairments, as distinct from curing existing impairments, can be non-stigmatizing at least for the individuals treated, ${ }^{2}$ then the argument that status enhancements reduce stigma cannot be used as a general argument in the favour of such a policy. Indeed it may even sometimes be the case that status enhancements could increase stigma. Consider new laws, passed for status enhancement reasons, which rule out some existing activities if they cannot be made accessible to all. Perhaps a ride in a theme park, or a restaurant entrance in a historic part of town, cannot be adjusted and the ride and the restaurant must close. Some may now resent the fact that they can no longer do what they once enjoyed and may start to single out wheelchair users to blame, thereby identifying and quite possibly stigmatizing them. Indeed, there is a more familiar problem. The costs of making material accommodations for disabled people, such as installing stair-lifts, very often fall on individuals or companies, rather than the tax payer. Those who find themselves out of pocket as a result may strongly resent those individuals for whose benefit the changes were made, and this could be evident through their behaviour. Arguments from stigma, then, cut both ways.

The question we have considered so far in this section is whether there is any good reason for favouring status enhancement over personal enhancement, or vice versa. We have assumed that it is an advantage in a policy if it avoids stigma, but this is doubly inconclusive. First, as we have seen, the claim that status enhancement is always less stigmatizing than personal enhancement is implausible, and second, there may be other concerns that will need to be weighed in the comparison. For example, the scope for effective mitigation of the adverse consequences of impairment through social change varies greatly. Where an impairment is very tightly connected to an adverse consequence - those who are

2 It may well be, though, that preventative treatment for a group is stigmatising, or otherwise detrimental, to those who have already the impairment. If this is right then it would be a further argument for status enhancement, although I cannot explore it further here. 
blind cannot achieve the enjoyments of visual experience, for example the social factors have much less significance and the balance seems to swing towards looking for personal enhancements. Where, however, the connection is more contingent, as in the example of restricted height, other forms of change may be more favoured. Quite obviously, such concerns about what might effectively be achieved must be relevant to choice of strategy. If it is true that little can be achieved by status enhancement, then a medical approach may well be appropriate. In other cases, however, if a medical approach promises little benefit, but social and cultural change could significantly improve the lives of disabled people then the balance conclusively shifts towards status enhancement.

So far, then, we have discussed two considerations - stigma and effectiveness - and have shown that neither of them is a universal reason for favouring one of the strategies over the other in all cases. But we should also consider other factors that would be desirable in a policy aimed to address disability, and see what significance they have for the question of choice of strategy. Take, for example, the argument that society should favour status enhancements on the ground that social and cultural change, once made, is permanent, and for the benefit of all. This implicitly contrasts with the idea that a policy of medical cure relies on attending one by one to all those who present with impairments. Not only does this mean that some people could be missed out, but also that a future change in medical priorities could leave people with impairments untreated. Hence, it could be argued, a policy of personal enhancement is fragile in a way in which a policy of status enhancement is not. However, while it seems right that the values of permanence and universality of benefit should be added to the list of desirable factors for disability policy, it is unclear that they decisively favour status enhancement. Social change can happen in two directions. If attitudes change adversely, those who have relied on status enhancements could find themselves cruelly exposed as attitudes harden, and beneficial changes are reversed. In that case an entire group will be made worse off, whereas if personal enhancement had been adopted then for those who have already benefited the change is permanent. Both approaches are fragile, in different ways.

Sometimes it is pointed out that status enhancements can have "overspill" benefits. This is particularly clear in the case of material change, specifically to the built environment, product design and new technology. Here there can be benefits for others. People with mobility problems are a wider set than those who might be included in a classification of disabled people. Mothers with young children, those children themselves, and the elderly, can all find the design of street furniture, shopping centres and even domestic appliances difficult or hazardous. Making them accessible can help people who are not disabled. But again, developments in medicine often have unexpected effects; notoriously Viagra was discovered by 
accident in the attempt to find a drug to treat heart conditions. Anything can have overspill benefits.

A further argument sometimes given in favour of status enhancements is that some people with disabilities refuse medical attention on the grounds that they have built their identity around their physical nature, and do not want to change. Yet one must also concede that there are many people who would love to rid themselves of their impairment, especially those with acquired disability. So, again the argument from identity cuts both ways, in that it can be used to support both types of policy for different individuals.

It can also be argued that status enhancements reduce risk. A society favouring status enhancements reduces risk to everyone. It reduces the risk, not of becoming impaired, but of suffering further losses of functioning consequent on becoming disabled. A world already adapted to the needs of people with impairments makes disability less of a disadvantage, and hence the prospect of possibly becoming disabled somewhat less threatening, at least to the preservation of one's existing way of life. Status enhancement goes some way to providing security for all, insofar as this is possible. ${ }^{3}$ It makes us all better off, whatever our fate. Yet, once again, the same thing can be said for personal enhancement. If a good cure exists, we can all be assured that even if we develop the impairment, and provided we have the right sort of access to medical services, then we will be insulated from some risk. The argument from risk, therefore, is an argument that disability policy spreads its benefits more widely than often thought, rather than argument for one type of strategy rather than another.

Yet another argument sometimes thought to give status enhancement an advantage is that it helps secure "affiliation". Other policies encourage the idea that society is divided into two groups, the able-bodied and the disabled, or the "normal" and the "disadvantaged" who need, or have received, help. Such a division undercuts the idea that everyone is an equal, and should be regarded and treated as such, deserving of equal respect. Although it is not inevitably the case that society must view itself as divided simply because one group receives help and another does not, nevertheless this possibly is avoided if the world is redesigned in a non-exclusive fashion. Status enhancement, in not singling out those who benefit from the policy, encourages social equality, which is a good for all, whether one is in the group which directly benefits from changes to the world or not.

Accordingly, successful policies of status enhancement simply erode disadvantage. As we noted above, anti-discrimination policies are a good

3 This account draws on, although does not pre-suppose, the "secure functioning" account of well-being set out in Wolff and de-Shalit (2007). 
model and illustration. It is taking a great struggle for women to achieve anything close to equal pay for equal work. The first generation of women to receive some benefit from such changes may have felt immensely grateful for their improved pay. But it would be very odd now for a woman to think that she owes gratitude to society for making the change. Similarly we may be approaching a situation in which, at least in new buildings, accessible design is taken for granted, and no wheelchair user should feel grateful that the architects have produced a building which he or she can enter just as easily as other people. These forms of accommodation encourage the idea of a society of equals, even if much else remains to be done. Ultimately there may be no perception of a distinction between a group needing help and a group that does not.

Inevitably, there is a possible response from those who favour personal enhancement. Removing impairments and making everyone more similar, so it might be alleged, would do even more to encourage feelings of affiliation, on the grounds that it is easier to affiliate with people who are like you than with people who are very different. Whether or not there is any empirical basis for these claims, it is, for obvious reasons, a dangerous argument, seemingly cutting against arguments for toleration of difference. And here, we come explicitly to the issue that has, perhaps, been implicit throughout the discussion to this point; when should difference be accommodated and when should it be removed? Policies of status enhancement accept difference; policies of personal enhancement attempt to eradicate it. In this way status enhancement seems to offer a level of respect for individuals as they are, rather than supposing that to respect someone is to make them fit some sort of social template. ${ }^{4}$ Something like this, surely, is behind the shared intuition that changing the world can be better than changing the person; it sends a message of acceptance of people as they are, rather than how we need them to be for the sake of convenience.

In sum, although personal enhancement looks to many people to be the obvious way to address disability, there are various reasons why, in many circumstances, status enhancement is either preferable or should be used as a supplement. We have looked at considerations of stigma, effectiveness, universality, permanence of benefit, overspill benefits, risk reduction, affiliation and toleration of difference. We should, of course, add financial cost too. With one exception, all of these values can be used in some cases to defend policies of status enhancement and in other cases to defend policies of personal enhancement (and perhaps the same

${ }^{4}$ I have discussed it in more detail in Wolff (2002) where I suggest that the view underlying the preference for difference is one of "individual essentialism": that each person has his or her own individual characteristics which should not be changed, at least unless the person is in favour of such change. 
considerations can be used by both sides in some cases). The one exception is toleration of difference, which appears to be able to support status enhancement but speaks against personal enhancement. Yet this is only one consideration among many, and with so many values in play it seems very unlikely that there will be any formula or algorithm to decide how to balance the considerations against each other. In the choice of strategies there will be both easy cases and hard cases, but no general argument that either strategy must always be followed.

\section{DISABILITY AND EQUALITY}

Nothing I have said so far depends on any particular theory of distributive justice, beyond the assumptions that, first, the claims of disabled people have weight on others, and second that the considerations discussed in the last section identify genuine values. Although not everyone would agree with these assumptions they are compatible with a wide range of views within the social democratic tradition. However, when thinking now about the question of the nature and depth of the claims of disabled people, it is apparent that there is a great deal of room for disagreement, even among those who are sympathetic to the idea of creating a society of equals. ${ }^{5}$

For this reason it may seem that this paper should have started by defending, or at least stating, a particular theory of equality, which could then be applied to the question of how disability should be treated in a society of equals. However, I deliberately avoided such a strategy on the grounds that it may well be that disability can teach us more about equality than equality can about disability. To explain, consider, for example, how one might have approached the issues of disability by assuming, say, a theory of equality of welfare. In the first instance, then, one's goal would be to ensure that people with disabilities had the same level of welfare as other citizens. One immediate observation is that on many studies it appears that those with at least some disabilities do not report different levels of happiness from others, and therefore could achieve equality of welfare without any special measures. (For discussion see Dolan and Kahneman 2008.) Second, whether or not this is not so, on such a view the idea of disability would be of no fundamental theoretical importance, and disability would simply be one threat, among others, to welfare. That may or may not be a welcome result. But finally, if welfare alone was the goal, then cash compensation would be, at least in the first instance, the

${ }^{5}$ As is well-known, views vary on three primary axes. First, what is currency of justice: welfare, resources, capability or something else? Second, what is the pattern: equality, priority (absolute or weighted) or sufficiency? Third, what role is there for responsibility? And let us cross-cut all of this with another distinction: does the discussion concern ideal theory or real-world policy? (See for example Wolff 2007) It seems evident that the choice on this matrix may well lead to quite different consequences for disability policy. 
appropriate form of addressing disability, and there would be no particular reason for wishing to pursue strategies of personal enhancement, targeted resource enhancement or status enhancement, unless these turned out to be better indirect strategies for increasing and then equalizing welfare. But the fact that we are attracted to policies of personal enhancement, targeted resource enhancement and status enhancement without having welfare improvement primarily in mind, appears to provide some evidence that we do not accept a theory of equality built purely on the currency of welfare. In reply it might be said that the attraction to such other strategies is based on opportunity for welfare, in that all of these strategies put individuals in a position where they have a better chance of pursuing their welfare for themselves (cf. Arneson 1989). Now while it is true that all the strategies mentioned do improve individual opportunity - that is their purpose - it is less clear that the policies discussed so far in this paper are attractive purely because they offer opportunity for welfare.

The theory of equality of resources may seem, at first sight, to be equally problematic, in that a disabled person may well have the same level of income and wealth as others, yet still be hampered in their life projects to a degree beyond that of others. However, when the concept of resources is extended to include internal as well as external resources, as, for example, in Dworkin's theory of equality of resources (Dworkin 1981), the account does better, and provides a rationale both for extra external resources, to make up for reduced internal resources (cash compensation, or targeted resource enhancement) or for personal enhancement (to improve internal resources). Yet if the only thing that matters is possession of resources it is hard to see why the approach of status enhancement is as important as it is, for status enhancement improves individual functioning without changing anyone's individual allocation of resources. The focus, then, is on what people can do, rather than what they have. Once more, emphasizing that the theory is one of opportunity for resources rather than resources alone could provide a rationale for status enhancement. Yet once more the reply is predictable; it is unclear that the sole attraction to status enhancement is that it improves individuals' opportunities for resources. For example, such a position leaves no room for the considerations of difference, affiliation, stigma and humiliation which played an important role in the intuitions behind a preference for status enhancement.

Consequently while I did not, in the opening sections, specify what the adverse consequences are that are suffered by people with disabilities, and therefore proceeded to draw on considerations which did not explicitly depend on any particular theory of equality, it seems that the discussion to this point does in fact make some assumptions about, or have some consequences for, the theory of the currency of justice. It seems that many of the arguments seem more at home within a capability view than a resource of welfare view (Sen 1980, 1999; Nussbaum 2000, 2006; 
Burchardt 2004; Wolff and de-Shalit 2007). Of the four strategies outlined for addressing disability, three - personal enhancement, targeted resource enhancement and status enhancement - were all directly concerned with the question of how it would be possible to improve an individual's capability for functioning. Now, of course, it is very likely that improving functioning is also likely to increase welfare and resources, but the purpose of the intervention is to improve functioning for a whole range of reasons, rather than merely as instruments in the pursuit of welfare or resources. Functionings likely to be boosted by status enhancement include affiliation and control over the environment, which seem to be valuable in themselves, independent of any further effects on welfare or resources.

Hence some version of the capability view seems to fit well with our shared intuitions about the appropriateness of different strategies for addressing disability. Yet this recognition comes at severe cost. One of the features of the capability view which makes it so appealing is its pluralism; its refusal to reduce different kinds of functioning to a single measure, or to suppose that there is some sort of privileged weighting between different kinds of functioning, such as life, bodily health, affiliation, control over the environment and emotional well-being, for example (Nussbaum 2000). This allows one to avoid shoe-horning different types of policies or considerations into a single, implausible, measure. Yet at the same time it becomes hard to see how to measure one person's capability performance against another. Of course there may well be some very clear cases in which one person does better than another on some kinds of functioning and no worse on others, or in which two people perform to the same level in all, but in every other case of comparison there will be room for disagreement about who is better off. Hence "equality of capability" is not a well-defined notion, and similar considerations affect any form of priority view. "Sufficiency of capability" in which everyone is to be brought to a high threshold level on all capabilities is both theoretically and practically appealing - provided we can define appropriate threshold points - at the level of ideal theory. But in the real world, where it is impossible to bring everyone to a high level of sufficiency on all kinds of functioning, it issues either no, or implausible guidance, apparently entailing that society should abandon those who cannot be brought up to the threshold (Casal 2007; Wolff and de-Shalit 2007).

In sum, then, although our intuitions about addressing disability seem to be based on a capability view of well-being, this leaves us in difficulties about how to move to practical applications. The difficulty is not so much what types of social policies we should follow - the previous sections have explored those issues - but how much of a society's resources should be devoted to addressing disability. Given that there are many groups with plausible claims for additional public spending, how do we know how much to spend on disability policy? And this is a problem both 
in the ideal world, with full social commitment to equality, and in the real world where the commitment to equality for all, including people with disabilities, is far more muted. In the real world, the question, we might say, is not of equality but of decency. Putting the question the other way round, we want to know when our societies have fallen below a threshold of decency, in which our collective behaviour towards people with disabilities is unacceptable, on what we might call liberal democratic, rather than strict egalitarian, grounds. To explore this is the task of the next section.

\section{DISABILITY AND RESOURCE ALLOCATION}

What, then, should be spent on disability policy to avoid the charge that we are unjustly neglecting the claims of people with disabilities to the point where we are treating such individuals below the level of decency? How can we know? It is one thing to argue that disabled people have valid claims for assistance, but another to decide what social weighting such claims should have. For example, it is sometimes suggested that some claims of justice should be sacrificed for the sake of economic efficiency. However, that is not my primary focus here. Rather, I want to consider how to weigh claims of disabled people against those of others who also have claims that egalitarians would consider to be claims of justice. In practice, this question of priority-setting comes down to the issue of whether there is a principle, or at least a clear argument or approach, available in order to judge whether or not attention to disabled people falls below an acceptable level.

The most radical suggestion is that the claims of disabled people have absolute priority, at least up to the point of equality with nondisabled people. On this view we should simply spend whatever it takes to ensure that people with disabilities are treated in a way that is in some important sense equal to those without disabilities. That is, it may be that current society is far from just, and there are good reasons for trying to reduce such injustice, but irrespective of how much progress we make on that project, disability should not be allowed to increase the degree of inequality in society. This seems, at first sight, a plausible approach, particularly if issues of disability are assimilated to those of pure discrimination. If lack of access to buildings, say, is treated as a violation of rights or of basic liberty, and it is agreed, with Rawls (1971), that basic liberty has priority over any issues of economic well-being, at least once society has reached a certain level of prosperity, then there should be no cost constraint on spending to equalize the position of those with disabilities, just as in a decent society racism or sexism cannot be justified on the basis of the cost of anti-discrimination policies, at least where overt discrimination is taking place. On such a view society has 
a duty simply to spend what it takes to overcome the discrimination suffered by disabled people, even in the non-ideal world in which we live.

Now, I would not deny that overt discrimination is a problem that many people with disabilities face on a regular basis, and in such cases rectification with no cost-constraint can be appropriate. However, the type of systematic disadvantage that disabled people inadvertently face as a result of social practices which have evolved over time seems to be something different; accidental consequences of policies which may well have been adopted for what were, at the time, good reasons. But there are many groups who can point out that they suffer similar indirect discrimination; such as women, people from ethnic or religious minorities, people who grew up in poverty or stressed family circumstances, and elderly people. If we argue that all of these groups, as well as disabled people, have claims that should be met without regard to the cost, it seems unlikely that any society has the resources to meet all valid claims, even if they are called issues of (indirect) discrimination. Hence we still need to know how to assess and balance the claims of disabled people against those of others. Simply claiming that people with disabilities are discriminated against does not supply an answer to this question in a world in which so many people suffer discrimination of a similar type.

A second approach starts from what looks like a less radical assumption; that even though it may not be accurate to say that such a thing as inaccessible design is a violation of the basic liberty of disabled people, nevertheless it denies disabled people equal opportunity with others, and as equal opportunity is an accepted principle in real world decent politics, once more there should be no limit on what is spent improving the opportunities of disabled people to bring them to the same level as non-disabled people. ${ }^{6}$

Even putting aside the question of whether other groups may have similar claims, the matter, however, is more subtle than it may seem, as there are at least two different ideas of opportunity, which are easily run together. Janet Radcliffe Richards (1997) brings out the distinction between two conceptions of equality of opportunity by considering the analogy of the distribution of shoes. Suppose ten athletes are running a race, but before they start five find that their running shoes are lost or stolen. There seems

${ }^{6}$ To ward off misunderstanding, I should say that in this section I am discussing views fully specified by the idea of equality of opportunity rather than any view with "equality of opportunity" in its name. So, for example, my criticisms of equality of opportunity are not directly addressed to the theories of "equality of opportunity for resources" or "equality of opportunity for welfare". However, the arguments of this section do have an indirect bearing on such theories, which I will bring out more fully in footnote 7 below. 
good reason here to "level down"; to insist that all athletes run barefoot, for otherwise the race will be unfair. Consider now a similar situation not with running shoes, but warm winter boots. Assuming that there is no further competitive advantage in having these boots, then there seems to be no case at all for levelling down; for making everyone equally uncomfortable by taking away their shoes. In one case the shoes are instruments in a competition, and to make the competition fair it is necessary to equalize access to the instruments; in the other situation there is no competition and the shoes are valued as instruments to a good - warmth and comfort that is not distributed competitively.

Now, if the idea of a running race is a good metaphor for making one's way through life, then there is a very good argument for strict equality of opportunity, so that the "winners" can emerge fairly and relevant features are rewarded. Equality of opportunity in this sense is rather like a controlled scientific experiment, where a number of factors are held constant to allow another to exert its influence. In a running race the salient factor should be running ability; in university selection, academic potential, and so on. These cases presuppose a competition for goods that are in scarce supply, with equality of opportunity needed in order to make the competition fair. We can call this "competitive opportunity", giving each person a fair chance of reaping unequal rewards.

However, this competitive model of society should seem very unattractive to those who believe in social equality, who are more likely to endorse a different idea of opportunity, where opportunity is considered as something rather closer to a good in itself, rather than merely a means to another good. This we can call "non-competitive" opportunity. For an illustration, consider what it is to bring up one's children with a good range of opportunity. Perhaps this means giving them access to a variety of social and cultural goods, such as music, craft, art, drama and sport, so that they can experiment and each find what suits them best. Opportunity, in this sense, is not access to a scarce good awarded in a competition, but rather providing access to goods that any number of other people can also enjoy.

We seem to be led to an apparently paradoxical conclusion: strict equality of opportunity should be considered a rather minor issue by those who support the egalitarian project of wanting to fashion society as some sort of community of equals. By contrast, strict equality of competitive opportunity makes a great deal of sense on an anti-egalitarian meritocratic conception of society, in which some rare social positions are prized. Equality of non-competitive opportunity - or at least giving it lexical priority over other concerns - may seem at first sight attractive to egalitarians, but on further reflection now seems a rather dated view, to be replaced with a form of sufficiency or priority of non-competitive 
opportunity view. ${ }^{7}$ For otherwise it requires levelling down; the equivalent of the removal of warm winter boots from everyone if there are not enough to go round.

Now it may be thought there is something odd about this argument, given that Rawls combines prioritarianism with a very strict equality of opportunity. But in fact the Rawlsian position brings out the issues very clearly. Suppose Rawls had, instead of the Difference Principle, argued for a principle of strict equality in distribution, where economic incomes were identical, jobs were all of equal status, and all equally challenging and enjoyable. In such a world it would be very hard to see the point of also arguing for a principle of equality of competitive opportunity. If all are to get prizes, and no one cares who wins or loses, it surely doesn't matter whether or not people start in front or behind the starting line, or who has running shoes and who does not. It is only because in a Rawlsian world there are differential positions of power and income that equality of opportunity is required. The more meritocratic - the more inegalitarian the world is, the more important equality of competitive opportunity.

Nevertheless, whatever one hopes for in the ideal world, in the real world differential rewards to talents can be very steep indeed and raise moral questions concerning access to differential positions. Being hampered in competition on the basis of irrelevant considerations such as race and sex is opposed even by those egalitarians who detest the income inequalities of the capitalist marketplace. Exclusion on the grounds of impairment may be objectionable on similar grounds. Consequently equality of competitive opportunity appears to be an urgent need in the real world, even if it would disappear as a demand in the ideal world. Yet even if we accept that there is an urgent real world need, it remains unclear what follows. Once we are considering real world policy it is hard to ignore cost constraints.

To illustrate the problem, consider the example of a severely disabled person who could be looked after at home by one carer, or could go out and work, alongside others, but would need the assistance of three carers to help with the additional burden of competing fairly in the workplace,

${ }^{7}$ Of course equality of non-competitive opportunity could be an element in a more complex theory, alongside the Pareto principle, and hence not an "all things considered" final theory. However, once the principle can be modified or over-ridden by other principles, it can no longer be pulled out as a "trump-card" in social argument: a much more complex argument is needed looking at the impact of any social policy on the whole range of principles that form the entire view. This is equally so on a complex view incorporating equality of opportunity for welfare. Once any theory of equality is modified by an efficiency principle it is silent on the question of what it entails for people with disabilities until the trade-off between efficiency and equality is specified. Hence even if it is true that disabled people are unequal in their opportunities for welfare nothing for social policy follows unless the rest of the theory is stated. 
and obtaining an ordinary job. Hence there is a significant net social loss following a policy of equality of opportunity and helping this person to participate in society on the same terms as others, for let us assume that the resources needed to help the person participate greatly outweigh any productive contribution their participation would bring. It may be that if society is very wealthy, with few social problems, then it may well take the view that, as a matter of justice, such provision should be made, and pride itself on its enlightened social policy, even at such cost. But in a less wealthy society, with a great array of social problems, the argument is a much harder one to make. Providing equality of competitive opportunity for disabled people could well mean the neglect of others who also have important social needs. Some sort of trade-off between different claims of justice seems necessary. But how can we tell which trade-offs are acceptable? We seem to be back where we started. An urgent priority still might not be the most urgent for society. It remains the case that we need a method to help decide how much society should spend on disability policy.

Another alternative is the theory of "declustering disadvantage" (see Wolff and de-Shalit 2007). As noted in the last section, on the view presented here, understanding the adverse consequences of disability requires some sort of pluralist view of well-being. Such adverse consequences cannot be reduced to lowered preference satisfaction, or lower enjoyment of resources (unless the notion of resources is stretched in such a way as to be a plural notion itself). Rather, people with disabilities often, if not always, suffer from many different disadvantages, such as reduced health; reduced life span; reduced opportunities for fulfilling work; for finding and developing social networks; for control over their lives; for a wide range of leisure activities, as well as a reduced living standard.

Now people with disabilities are not alone in suffering in many of these ways, of course, and the theory of well-being that underlies the theory of disability should be no different from the theory that is used to assess the well-being of all members of society; that is a pluralist theory of which the capability theory of Sen and Nussbaum is the leading model. However, the difficulties of using any type of pluralist account of well-being within the theory of distributive justice creates notorious problems, as already noted: unless the categories can be weighed against each other - and to endorse pluralism is to deny that this is possible - how can the theorist or policy maker decide which of two people is the better off? Is a person who enjoys good bodily health, but is socially isolated, better or worse off than a person with mobility problems who has a rich social network? Even if there is broad consensus that the worst-off should be given special priority even if not absolute priority - in real-world government programmes, how are the worst off to be identified? 
The truth appears to be, however, that this is a theoretical difficulty which is not so clearly replicated in practice. The worst off are those who do badly on a significant number of categories of functioning, and so will tend to turn up near the bottom of the ordering however (within reason) those different categories are weighted. There are people who suffer from what we can call a clustering of disadvantage. For example, people who lack control over their environment, or have poor social networks, and thus low affiliation, often live shorter lives, and in worse health, than others (Marmot 2004; Wilkinson 2005). Those who fear assault or robbery, show similar effects, and often take steps to protect themselves which expose them to other risks, such as not going out of the house, and thereby losing or not developing social networks (Klinenberg 2002). Against a background in which disadvantage clusters, to the extent that the least advantaged can be identified fairly easily, the priority of helping the least advantaged can then be interpreted as an injunction to "decluster disadvantage", i.e. to try to rearrange society so that the question of who is worst off becomes difficult and controversial, with no obvious answer. In practice governments should try to identify and act upon "corrosive disadvantages" - those which cause other disadvantages - and "fertile functionings" - those that spread their good effects elsewhere. By doing so governments can attempt to turn the theoretical difficulty of identifying the least advantaged into a practical one, where there is no longer a clearly worse off group in society.

If it is true that - as seems likely - people with disabilities suffer from a cluster of disadvantages, understood as doing relatively poorly on a range of important capabilities or categories of functioning, then addressing their situation in the most effective way will be a high social priority, perhaps among others of comparable strength. To decide how to act, governments have, though, to take into account the total effects of the policy: its benefits for disabled people, and for others, as described above, and the opportunity cost of spending resources this way rather than another. However, rather than a simple "cost-benefit" analysis, on this theory governments must ask: is this the most effective way of declustering disadvantage, and thereby giving priority to the worst off? ${ }^{8}$ Action for people with disabilities will be a priority for as long as this is among the most effective way of declustering disadvantage: i.e. breaking up clusters of relatively low functioning among several vectors of important functioning.

To see the strength of this approach consider the puzzle we were left with in connection with the discussion of equality of opportunity: roughly that an affluent society should possibly spend considerable resources in

${ }^{8}$ Of course safeguards are needed to avoid declustering by spreading misery, but to go into this is beyond the scope of this paper. 
helping disabled people compete on equal terms in the workplace, but in a less affluent society exactly the same policy would be too expensive. What can make the difference? The short answer is that in a very affluent society disabled people, excluded from the workplace, are likely to be among the worst off in society, whereas in a less affluent society it may well be the case that either other people will be worse off than people with disabilities, or for people with disabilities there are other urgent problems which are more basic, yet less expensive to address, than lack of access to the workplace. Hence as background circumstances change, so do social priorities in terms of attempts to break up the most serious clustering of disadvantage.

In sum, then, we will have unjustly neglected the claims of people with disabilities if we find that they are among the worst-off groups in society, in the sense of suffering from the most serious clustering of disadvantage. In an affluent society disabled people who lack access to the workplace may well be among the worst off, in this sense. In a less affluent society, with a series of social problems, clustering of disadvantage is likely to take a different form and the most immediate need to take steps to decluster disadvantage is unlikely to include very expensive measures to assist disabled people to take part in the workplace, whether the least advantaged include disabled people or not. Although a great deal more needs to be said, the theory of declustering disadvantage seems a promising approach to priority setting within a broadly egalitarian view.

Still, there are, as always, objections. It will be said that on such a view disabled people who enjoy a strong social network, who have a good control over their lives, who have been well-educated and have a decent income, and therefore do not fall into the group for whom disadvantages cluster, should not receive support from the state for their disability. In the limit case - where there are no adverse consequences at all - this may well be correct, but, it will be said, in other cases there are still some adverse consequences, most notably for health. And, it will be added, how good an individual's social networks are, how well-educated they are, and how good a job they have, should have no bearing on what society provides for their health. Indeed, it may be continued, the way to respond to the pluralism of advantage and disadvantage is not to attempt to decluster disadvantage, but to treat each area as a "separate sphere", as advocated by Walzer (1983) and Miller (1999) (see also Elster 1992). On this view people who are ill should receive attention from the state on the basis of principles that refer only to health and not to that person's success in other walks of life; similarly for education, for housing, for employment, or whatever spheres one wishes to propose for government action.

This is a very attractive idea and certainly we do not want doctors deciding treatment priorities between patients depending on how individuals are doing in other non-health related aspects of their life, such 
as what job they have. And rich or poor, if you have a mobility problem you should get priority parking. Yet there are several problems with the separate spheres argument, of which the most pressing in this context can be stated simply: how does government decide how much of its scarce resources to put into each sector? "Separate spheres" simply returns us to the problem we started with.

Nevertheless, it may be thought that the declustering disadvantage approach has too high a cost. Does it not require society to discriminate between disabled people on the basis of how well they are doing in different aspects of their lives? And does it not require people such as doctors, social workers and even university admissions officers to be agents of such discrimination? This is not an appealing prospect: it can seem unfair; overly intrusive; and requiring judgment from office holders who do not have the training or expertise to exercise it over many sectors.

These are all fair and important points, but they have an answer; the division of labour. To explain, the theory of declustering disadvantage is not a theory about how doctors and social workers should allocate their time and resources. Very often, although not always, they should act as if the separate spheres argument is correct. The idea of declustering disadvantage is aimed at a high level, identifying the sorts of considerations that should be taken into account across the cabinet office table, answering questions of where government should concentrate its efforts, and how to set priorities within each sphere of activity. Much more detail needs to be added, but this, at least, provides a sketch of a theoretical approach that can inform real-world public policy at the level of budget allocation as well as in the spending of those budgets. The budget for addressing disability should, at least in part, be determined on the basis of what would be the most effective strategy towards declustering disadvantage in society.

\section{REFERENCES}

Arneson, R. 1989. Equality and equal opportunity for welfare. Philosophical Studies 56: 77-93. Burchardt, T. 2004. Capabilities and disability: the capabilities framework and the social model of disability'. Disability \& Society 19: 735-51.

Casal, P. 2007. Why sufficiency is not enough. Ethics 117: 296-326.

Dolan, P. and Kahneman, D. 2008. Interpretations of utility and their implications for the valuation of health. The Economic Journal 118: 215-34.

Dworkin, R. 1981. What is equality Part 2: equality of resources. Philosophy and Public Affairs 10: $283-345$.

Elster, J. 1992. Local justice. New York: Russell Sage Foundation.

Klinenberg, E. 2002. Heat wave. Chicago: University of Chicago Press.

Marmot, M. 2004. Status syndrome. London: Bloomsbury.

Miller, D. 1999. Principles of social justice. Cambridge, MA: Harvard University Press.

Nussbaum, M. 2000. Women and human development. Cambridge: Cambridge University Press.

Nussbaum, M. 2006. Frontiers of justice. Cambridge, MA: Harvard University Press. 
Rawls, J. 1971. A theory of justice. Oxford: Oxford University Press.

Radcliffe Richards, J. 1997. Equality of opportunity. Ratio 10: 253-79.

Sen, A. 1980. Equality of what? In Tanner lectures on human values, ed. S. McMurrin, 195-220. Cambridge: Cambridge University Press.

Sen, A. 1999. Development as freedom. Oxford: Oxford University Press.

Walzer, M. 1983. Spheres of justice. New York: Basic Books.

Wilkinson, R. G. 2005. The impact of inequality. London: Routledge.

Wolff, J. 2002. Addressing disadvantage and the human good. Journal of Applied Philosophy 19: 207-18.

Wolff, J. 2007. Equality: the recent history of an idea. Journal of Moral Philosophy 4: 125-36.

Wolff, J. forthcoming. Disability among equals. In Philosophy and Disability, ed. K. Brownlee and A. Cureton. Oxford: Oxford University Press.

Wolff, J. and de-Shalit, A. 2007. Disadvantage. Oxford: Oxford University Press. 